\title{
Haematological abnormalities in patients with severe community acquired pneumonia who did not require mechanical ventilation and in patients with severe pulmonary tuberculosis
}

\author{
Géza Bozóky* and Éva Ruby \\ Department of Pulmology and Internal Medicine, Hospital of Bács-Kiskun County Municipality, Bács-Kiskun County
}

\begin{abstract}
During the 10-year follow-up period (2008-2019) authors analyzed the different hematological changes in 1280 hospitalized patients with sever community acquired pneumonia (CAP) who did not require mechanical ventilation. The severity of illness was identified by the „pneumonia serverity index” and by the „CURB” (confusion, urea nitrogen, respiratory rate, blood pressure) severity scores. Normochromic-normocytic type of aneamia was diagnosed in $12 \%$ of patients: hypocromic microcytic type of anemia was observed on $8 \%$ of patients: immune-mediated-hemolytic anemia occurred in 6 patients. Usual degree of leucocytosis with left shifted periferial blood smear was detected in $32 \%$ of patients: extreme degree of leucocytosis was observed in 20\%, leucopenia (granulocytopaenia) occured in 16\% of patients. Elevated plateled count was defined in $18 \%$ while thrombocytopaenia was found in $6 \%$ of patients.

Authors prospectively followed 380 patients with pulmnary tuberculosis according to the characteristics of chest radiograph and sputum Ziehl-Neelsen's stain positivity, and a result of quantiferon test. In 380 patients with severe pulmonary tuberculosis anemia was present in 52\% of patients: leukocytosis occured in $20 \%$ leucopenia, granulocytopedia and lymphopenia was observed in $16 \%$ of patients. Elevated platelet count occured in $26 \%$ which was compicated with deep vein leg thrombosis in 18 patients. Dysmyelopoietic bone marrow alteration with peripheal pancytopenia was diagnosed in one case as the result of mycobacterial sespsis. This survey has revealed that the various haematological abnormalities are common in cases of community acquired pneumonia, and in patients with severe pulmonary tuberculosis. The other clinical consequence is that the special haematological alterations, such as extreme leucocytosis, leucopenia, granulocytopenia and severe degree of anemia are useful indicators of the severity of lower respiratory tract infection.
\end{abstract}

\section{Introduction}

Community acquired pneumonia (CAP) is an important healthcare concern, and is the most common cause of death associated with infectious disease and the sixth most comon cause of death [1-3]. The annual incidence rate in the USA 6/1000 in the 18-39 age group, and $34 / 1000$ in people aged 75 [3]. Admission to the hospital in patients with CAP is needed in $20-40 \%$ and about $5-10 \%$ of these patients are admitted to intnsive care unit (ICU) $[3,4]$. The mortality rate of CAP in outpatients setting is in the range of $<1-5 \%$, but among patients who require hospitalization, the rate averages $12 \%[1,3]$.

Severe CAP (sepsis syndrome and septic shock syndrome) has been separeted from cases of less severe pneumonia requiring hopsitalization, because of the high mortality rate (up to 50\%) Although there is no uniformly accepted definition of sever CAP, the original ATS guidelines, and in one more recent study nine criteria was identified for severe illness, and the presence of any one was used to define severe CAP [1-7]. The nine criteria for severe CAP were divided into five "minor" criteria that could be present on admission and four „major" criteria $[3,7]$. The minor criteria included respiratory rate $\geq 30$ / min, Pao2/Fio2 $<250$, bilateral or multilobar pneumonia, systolic BP $\leq 90 \mathrm{Hgmm}$, and diastolic $\mathrm{BP} \leq 60 \mathrm{Hgmm}$. The major criteria included a need for mechanical ventilation, an increase in the size of infiltrates by $>50 \%$, septic shock or the need for pressors and acute renal failure. During the 10 year follow-up period (2008-2018) we have analyzed prospectively the different hematological changes in 1280 hospitalized patients with severe CAP, who didn't required mechanical ventilation. In the other part of this survey we retrospectively followed 380 patients with pulmonary tuberculosis according to the characteristics of chest radiograph and Ziehl-Neelsen stain positivity, and quantiferon test in association with haematological changes.

\section{Patient and methods}

During the 10 yeras follow-up period (2008-2018) we identified a severe community-acquired pneumoia in 1280 patients. For all patients with severe CAP, diagnostic testing should include a chest radiograph, routine laboratory tests (complete blood counts, serum sugar and electrolytes, hepatic enzymes and test of renal function). All admitted patients have oxygen saturation assessed by oxymetry. Artrial blood gas has been obtained in each patient with severe CAP. For he identification of the pathogen microorganism the diagnostic test has included a sputum Gram stain and culture. Two sets of blood

*Correspondence to: Géza Bozóky, Department of Pulmology and Internal Medicine, Hospital of Bács-Kiskun County Municipality, Bács-Kiskun County, E-mail: bozokyg@freemail.hu

Received: September 03, 2019; Accepted: September 20, 2019; Published: September 24, 2019 
Bozóky G (2019) Haematological abnormalities in patients with severe community acquired pneumonia who did not require mechanical ventilation and in patients with severe pulmonary tuberculosis

cultures have been drawn before initiation of antibiotic therapy, and may help to identify presence of bacteriemia and of resistant pathogen. When Legionella airways infection was suspected in patients with severe CAP, we measured of urinary antigen. Table 1 displays disease state characteristics at baseline for all patients with severe CAP. The identification of pathogen microorganism by sputum Gram's stain and culture, blood culture, urine test, and serologic testing have been established in only small proportion of patients: Streptococcus pneumoninae $24 \%$ staphylococcus $12 \%$ haemophylus influanze $10 \%$ atypical pathogens (M. pneumoniae, Legionella species) $10 \%$ Klebsiella species $6 \%$. Patients were stratified into pneumonia severity index risk classes (I-V) and CURB-65 (0-5) risk strata.

During the same time (2008-2019) we 380 patients with severe pulmonary tuberculosis according to the clinical signs and symptoms, to the characteristics of chest radiograph, and to the positive sputum Ziehl-Neelsen's stain/and quantiferon test (Table 2). We analyzed the extent and severity of haemotological abnormalities in all patients with severe CAP and with severe pulmonary tuberculosis (Table 2). We assessed the haemoglobin conentration, hematocrit value, the serum iron level, saturation index a free iron-brinding capacity, complete blood count (white blood cells, platelet counts)and different other special laboratory test were done (serum LDH concentratio, direct and indirect Coombs-test, serum haptoglobin value, urinary sedimentation and hemoglobin analysis, measurement of liver enzymes) for the detection of autoimmune-hemolytic anemia. In only one patient a bone marrow aspiration and crista trephine biopsy was made because of a pancytopaenia in a patient with mycobactrial sepsis.

\section{Results}

During the 10 year follow up period we identified severe community acquired pneumonia in 1280 patients. Severe lower respiratory tract infection definide the presence of acute radiographic infiltrates: multilobar, bilateral infiltrates of the lung and coexistent clinical symptoms and signs were detected in most of the pateints (Table 1). Severe from of pneumonia was classified in all of the patients according to the clinical symptoms (high temperature, tachypnea, tachycardia, altered mental status, low systolic and diastolic blood pressure), and laboratory findings (low oxgen saturation, leucocytois, left shifted blood smear, increased blood sugar and urea nitrogen level). Patients were stratified into pneumonia severity index risk classes I-V and CURB-65 4 strata. During the same period and quantiferon test positivity (Table 3) (2008-2019). We diagnosed pulmonary tuberculosis according to the characteristics of radiographic pulmonary infiltrates, and the positive result of the sputum Ziehl-Neelsen's stain (Table 3). The severity of pulmonary tuberculosis was detrmined by clinical symptoms (high temperature, weight loss, tachypnea, dyspnoe, tachycardia), laboratory findings (increased C-reactive protein, anemia, low oxygen saturation), positive results of sputum Ziehl-Neelsen's stain and characteristics of radiographic infiltrates.

\section{Hematological changes}

Anemia occurred in $20 \%$ of the patients identified with community acquired pneumonia, usual degree of leucocytosis with left shifted blood smear was detected in $32 \%$ of patients with CAP. Extreme degree of leucocytosis (WBC>20x10/1) was diagnosed in $20 \%$ in the preferial blood smear some myelocytes, metamyelocystes and promyelocytes can be seen. Leucopenia-granylocytopenia occurred in $16 \%$ while increased platelet count was observed in $18 \%$ of patients with CAP. In this group we obseved autoimmune-hemolytic anemia in 6 patients, while in the other group there was no immune-mediated hemolytic
Table 1. Baseline characteristics of patients with severe CAP

\begin{tabular}{|c|c|c|}
\hline Characteristics & Numbers & Percent\% \\
\hline \multicolumn{3}{|l|}{ Demographic factors } \\
\hline \multicolumn{3}{|l|}{ Age } \\
\hline$>50$ years & 720 & - \\
\hline$\geq 65$ years & 560 & - \\
\hline \multicolumn{3}{|l|}{ Physical examination findings } \\
\hline Temperature $\geq 39$ & 878 & 68 \\
\hline Pulse $\geq 125 / \mathrm{min}$ & 1136 & 88 \\
\hline Systolic blood pressure $<90 \mathrm{~mm} \mathrm{Hg}$ & 962 & 75 \\
\hline Diastolic blood pressure $\leq 60 \mathrm{~mm} \mathrm{Hg}$ & 841 & 66 \\
\hline Respiratory rate $\geq 30 / \mathrm{min}$ & 1090 & 85 \\
\hline Altered mental status & 128 & 10 \\
\hline \multicolumn{3}{|l|}{ Laboratory and radiograph finding } \\
\hline Blood urea nitrogen $>20 \mathrm{mg}$ & 296 & 23 \\
\hline Glucose $\geq 250 \mathrm{mg} / \mathrm{dl}$ & 314 & 24 \\
\hline Hematocrit $<30 \%$ & 256 & 20 \\
\hline Sodium $<130 \mathrm{mmol} / 1$ & 316 & 25 \\
\hline Oxygen saturation $<90 \%$ & 1190 & 93 \\
\hline $\mathrm{PaO} 2<60 \mathrm{mmHg}$ & 983 & 77 \\
\hline One lobular infiltrates & 178 & 14 \\
\hline Multilobular infiltrates & 691 & 54 \\
\hline Bilateral multilobular infiltrates & 503 & 39 \\
\hline Pleural effusion & 329 & 26 \\
\hline
\end{tabular}

Table 2. Haemtological changes in patients with severe CAP, and in patients with severe pulmonary tuberculosis

\begin{tabular}{|l|c|c|c|c|}
\hline \multirow{2}{*}{ Haematological characteristics } & \multicolumn{2}{|c|}{$\begin{array}{c}\text { CAP-group } \\
\text { n=1280 }\end{array}$} & \multicolumn{2}{c|}{$\begin{array}{c}\text { Tuberculosis-group } \\
\text { n=380 }\end{array}$} \\
\cline { 2 - 5 } & Number & \% & Number & \% \\
\hline Anemia & \multicolumn{2}{|c|}{} & 159 & 42 \\
\hline $\begin{array}{l}\text { Normochromic-normocytic: } \text { hgb }<8 \\
\text { mmol/1 }\end{array}$ & 153 & 12 & & \\
\hline Anemia & & & 38 & 10 \\
\hline $\begin{array}{l}\text { Hypocromic-microcytic:hgb }<8 \\
\text { mmol/1 }\end{array}$ & 102 & 8 & - & - \\
\hline $\begin{array}{l}\text { Autoimmun-hemolytic anemia } \\
\text { Leucoytosis (usual degree):WBC } \\
\text { 12-20x10/1 }\end{array}$ & 610 & 32 & 76 & 20 \\
\hline $\begin{array}{l}\text { Extreme degree of } \\
\text { leucocytosis:WBC }>20 x 10 / 1\end{array}$ & 256 & 20 & - & - \\
\hline Leucopenia:WBC<4x10/1 & 205 & 16 & 68 & 18 \\
\hline $\begin{array}{l}\text { Granulocytopenia: } \\
\text { granulocytes }<0,8 x 10 / 1\end{array}$ & 205 & 16 & 68 & 18 \\
\hline Thrombocytosis:platelet $\geq 200 x 10 / 1$ & 230 & 18 & 99 & 26 \\
\hline $\begin{array}{l}\text { Thrombocytopenia:platelet } \\
<100 x 10 / 1\end{array}$ & 205 & 6 & 8 & 2 \\
\hline
\end{tabular}

anemia diagnosed. The most common hematological alteration in the 380 patients with pulmonary tuberculosis was anemia (52\%) and thrombocytosis (26\%). Leukocytosis occured in 20 percent in patients without an extreme degree of leucocytosis. Leucopenia and granulocytopaenia were defined in $18 \%$ of patients with pulmonary tuberculosis. There was only one patient with pancytopaenia in the group of pulmonary tuberculosis: the bone marrow aspiration and biopsie revealed dysmelopeietic changes (Table 3).

\section{Discussion}

During the 10 year follow-up period authors retrospectively analyzed the different haematological changes patients with severe community acquired pneumonia, and in patients with pulmonary tuberculosis. This study surveys the extent and severity of hematological abnormalities and a correlation between the hematological changes 
Bozóky G (2019) Haematological abnormalities in patients with severe community acquired pneumonia who did not require mechanical ventilation and in patients with severe pulmonary tuberculosis

Table 3. Baseline characteristics of patients with severe pulmonary tuberculosis, $n=380$

\begin{tabular}{|l|c|c|}
\hline Characteristic & Numbers & Percent (\%) \\
\hline Demographic factors & 231 & - \\
\hline Age & 149 & - \\
\hline$>40$ years & & \\
\hline$>60$ years & 344 & 90 \\
\hline Physical examination findings & 329 & 60 \\
\hline Temperature $>38^{\circ} \mathrm{C}$ & 340 & 89 \\
\hline Weight loss $>10 \mathrm{~kg}$ & 328 & 86 \\
\hline Chest pain & 132 & 35 \\
\hline Shortness of breath & 172 & 45 \\
\hline Haemoptoe & 168 & 44 \\
\hline Systolic blood pressure $<90$ mmHg & & \\
\hline Diastolic blood pressure $<60$ mmHg & 380 & 100 \\
\hline Microbiological and radiograph findings & 286 & 80 \\
\hline Sputum Ziehl-Neelsen stain pozitivity & 100 & 26 \\
\hline Quantiferon test & 87 & 23 \\
\hline Bilateral multilobular patchy infiltrates & 286 & 80 \\
\hline Bilateral micronodular infiltrates & & \\
\hline Bilateral multilobular infiltrates with cavitation & \\
\hline
\end{tabular}

and the severity of pulmonary infectious illness. Community acquired pneumonia remains a common and serious illness, despite the availability of potent new antimicrobials. In the United States, pneumonia is the 6 leading cause of death and the number one cause of death from infectious diseases [3]. All patients with community acquired pneumonia should have established an early correct diagnosis, the presence of complications and the severity of the illness by clincal laboratory and radiographic findings. The major variables that influence the specturm of etiological agent and the initial approach to therapy are the severity of illness at initial presentation, the presence of coexisting illness, and the presence of identified clinical risk factors for drug-resistant and unusual pathogens [3]. The recognition and analysis of the hematological abnormalities in associations with lower rspiratory tract infection and pulmonary tuberculosis can give some new valuable information to define the prognostic score of the patient's diseases, and the severity of the infectious illness [2]. Normocytic and microcytic type of anemia is one of the most frequent blood disorders in patients with severe community acquired pneumonia and most often in patients with pulmonary tuberculosis [8]. Immune- mediated hemolytic anemia is a very rare hematological disorder in patients with CAP: the incidence of this blood disorder can occur in patients with CAP who can have mixed infection involving both bacterial and "atypical” pathogens [3]. Leucocytosis with left-shifted blood smear is a very common and usual additional hematological change in both infectious groups. The presence of extreme degree of leucocytosis with myeloid precursors in the peripheral blood pulmonary infections. Pancytopaenia is a rare, but severe blood disorder in association with respiratory tract infection due to the myelosupression of bacteriemia. Fort he diferentiation between pulmonary infection and primary hematological diseases (dysmyelopoietic syndrome, acute hemoblastosis, involvment of bone marrow by lymphoma or other solid malignant disease) crista Jamshidi's biopsy is indicated. An extreme high platelet count accompanied with leucopenia and with severe anemia represents a very sensitive predictive (risk) factor of the severity of the illness in patients with pulmonary tuberculosis [10-12].

Our study demonstrates that a potential advantage can be obtained by the immediate recognition of blood disorders in patients with severe acute respiratory tract infection and in patients with pulmonary tuberculosis for prediction of the severity of the pulmonary infection.

\section{References}

1. Hoare Z, Lim WS (2006) Pneumonia: update on diagnosis and management. BMJ 332: 1077-1079. [Crossref]

2. Ewig S, Torres A, Woodhead M (2006) Assessment of pneumonia severity: a European perspective. Eur Respir J 27: 6-8. [Crossref]

3. American Thoracic Society (2001) Guidelines for the management of adults with community acquired pneumonia. Diagnosis, assessment of severety, antimicrobial therapy and prevention. Am I Respir Crit Care Med Diagnosis 163: 1730-1754. [Crossref]

4. Laterra PF, Garber G, Levy H, Wunderink R, Kinasewitz GT, et al. (2005) Severe community-acquired pneumonia as a cause of severe sepsis. Data from the PROWESS study. Crit Care Med 33: 952-961. [Crossref]

5. Lim WS, Van der Eerden MM, Laing R, Boersma WG, Karalaus N, et al. (2003) Defining community acquired pneumonia severity on presentation to hospital: an international deviation and validation study. Thorax 58: 377-382. [Crossref]

6. Ewig S, Ruiz M, Mensa J, Marcos MA, Martinez JA, et al. (1998) Severe communityacquired pneumonia: assessment of severity criteria. A J Respir Crit Care Med 158 1102-1108. [Crossref]

7. Fine MJ, Auble TE, Yealy DM, Hanusa BH, Weissfeld LA, et al. (1997) A prediction rule to identify low-risk patients with community-acquired pneumonia. $N$ Engl $J$ Med 336: 243-250. [Crossref]

8. Coburn RJ, England JM, Samson DM, Walford DM, Blowers R, et al. (1973) Tuberculosis and blood disorders. Br J Haematol 25: 793-799. [Crossref]

9. Aujesky D, Auble TE, Yealy DM, Stone RA, Obrosky DS, et al. (2005) Prospective comparasion of three validated prediction rules for prognosis in community-acquired pneumonia. Am J Med 118: 384-393. [Crossref]

10. Glasser RM, Walker RI, Herion JC (1970) The significance of haematologica abnormalities in patients with tuberculosis. Arch J Med 125: 691-695. [Crossref]

11. Maartens G, Willcox PA, Benatar S (1990) Miliary tuberculosis: Rapid diagnosis, hematologic abnormalities and outcome in 109 treated adults. Am J Med 89: 291-296. [Crossref]

12. Kinoshita M, Ichikawa Y, Koga H, Sumita S, Oizumi K (1994) Re-evaluation of bone marrow aspiration in the diagnosis of miliary tuberculosis. Chest 106: 690-692. [Crossref]

Copyright: (C2019 Bozóky G. This is an open-access article distributed under the terms of the Creative Commons Attribution License, which permits unrestricted use, distribution, and reproduction in any medium, provided the original author and source are credited. 